\title{
Qualidade do ajuste da isoterma de Freundlich e Langmuir-Freundlich*
}

\author{
$\underline{\text { Livia Maria Pierini }}^{\dagger} \quad$ Fabricio Goecking Avelar $^{\dagger}$ \\ Instituto de Ciências Exatas, ICEx, UNIFAL-MG, \\ 37.130-000, Alfenas, MG \\ E-mail: liviam.pierini@gmail.com, fabricio@unifal-mg.edu.br
}

\section{RESUMO}

A adsorção é o acúmulo de um determinado elemento ou substância na interface entre a superfície sólida e a solução adjacente [3]. O fenômeno da adsorção acontece em inúmeras situações cotidianas como, por exemplo, nos purificadores de água de uso doméstico que utilizam carvão aditivado para remover, por meio de adsorção, impurezas contidas na água e nos catalisadores dos automóveis que adsorvem monóxido de carbono (CO) sobre a superfície do catalisador. Para avaliar a capacidade adsortiva de materiais, são utilizadas isotermas. Dentre as mais utilizadas, estão a isoterma de Freundlich e a de Langmuir-Freundlich, que podem ser expressas respectivamente por

$$
y(C)=K C^{b}+e \quad \text { e } \quad y(C)=\frac{K C^{b} M}{1+K C^{b}}+e,
$$

em que $y$ é a quantidade de soluto adsorvido, $K$ é o parâmetro de afinidade, $C$ é a concentração de equilíbrio do soluto na solução, $M$ é o parâmetro que indica a capacidade máxima de adsorção, $b$ é o parâmetro que representa o grau de heterogeneidade da superfície do adsorvente e $e$ é o erro aleatório.

Os modelos expressos em (1) são não lineares, o que impede o uso do método dos mínimos quadrados para estimar os seus parâmetros. Para contornar essa dificuldade, é possível utilizar linearizações dos modelos ou métodos numéricos iterativos, como o método de Gauss-Newton e o de LevenbergMarquardt.

Ao se estimar parâmetros, deseja-se que as estimativas obtidas sejam precisas e acuradas para que o pesquisador tire conclusões adequadas a partir do modelo ajustado. Desta forma, este trabalho objetiva avaliar as estimativas dos parâmetros das isotermas de Freundlich e Langmuir-Freundlich obtidas a partir do método de Gauss-Newton e do método de Levenberg-Marquardt.

Para avaliar as estimativas dos parâmetros da isoterma de Freundlich, foram simuladas 1.000 séries de dados com concentrações variando de 0,5 a 100 e tamanhos amostrais de 9, 12, 15, 16, 30 e 60 a partir do modelo com parâmetros $K=71$ e $b=0,2$ [2]. Para a avaliação das estimativas da isoterma de Langmuir-Freundlich, foi empregada a mesma metodologia adotada para a isoterma de Freundlich. Nesse caso os parâmetros utilizados foram $K=1, b=0,5$ e $M=5$ [1]. A acurácia e a precisão das estimativas dos parâmetros foram avaliadas utilizando-se o viés médio relativo (VMR) e o erro quadrático médio (EQM), expressos respectivamente por

$$
V M R=\frac{100}{N \theta} \sum_{i=1}^{N}\left|\widehat{\theta}_{i}-\theta\right| \quad \text { e } \quad E Q M=\frac{1}{N} \sum_{i=1}^{N}\left(\widehat{\theta}_{i}-\theta\right)^{2}
$$

em que $\widehat{\theta}_{i}$ é o valor estimado do parâmetro do modelo na $i$-ésima amostra, $\theta$ é o valor real do parâmetro e $N$ é o total de amostras simuladas. Foi utilizado o software R [4].

Na Figura 1, são apresentados os gráficos para o erro quadrático médio e para o viés médio relativo dos parâmetros $K$ e $b$ da isoterma de Freundlich obtidos via método de Gauss-Newton e LevenbergMarquardt.

\footnotetext{
${ }^{*}$ O presente trabalho foi realizado com apoio financeiro da Fundação de Amparo a Pesquisa do Estado de Minas Gerais (FAPEMIG).

†bolsista de Iniciação Científica PROBIC/UNIFAL-MG
} 

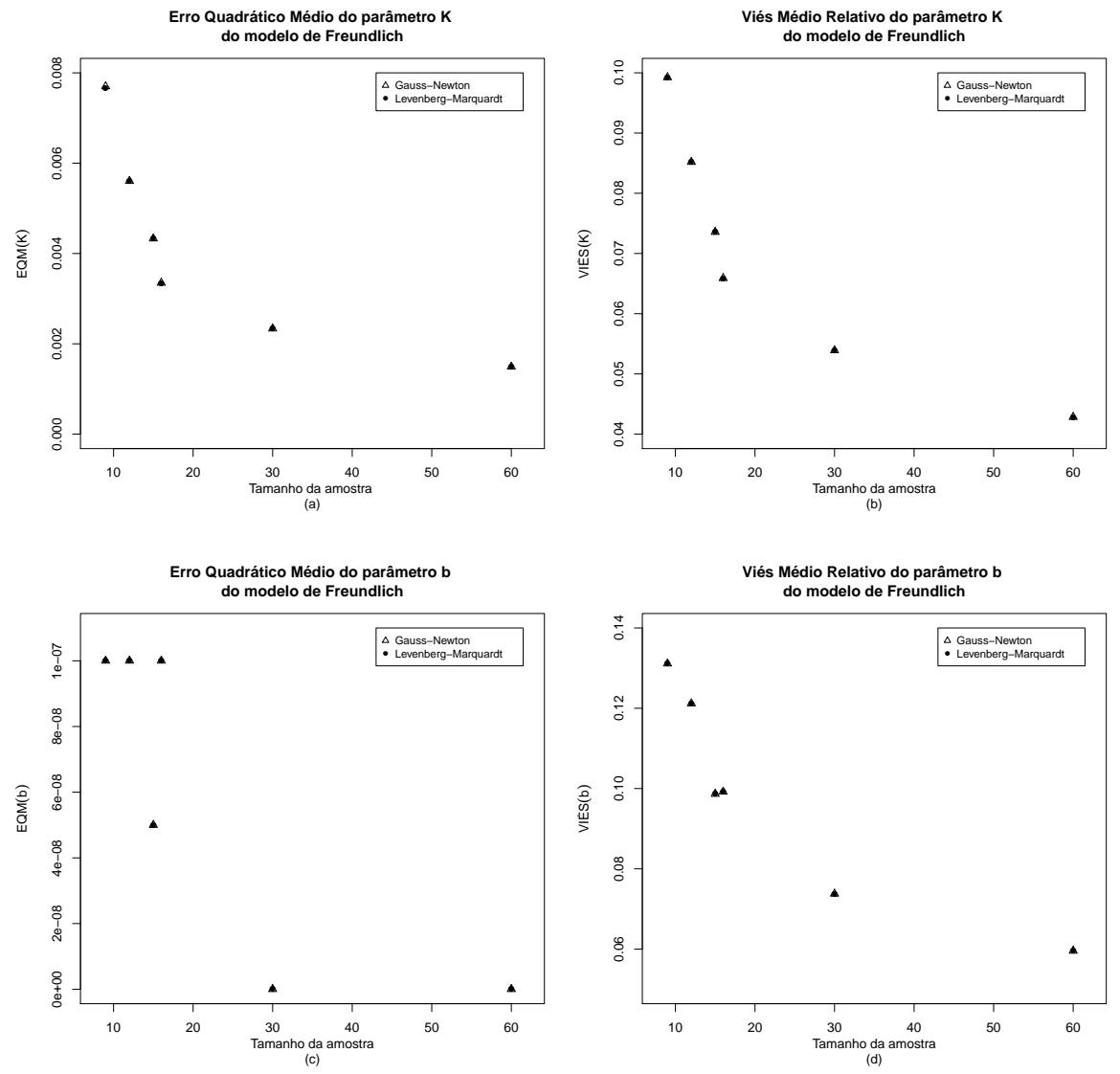

Figura 1: Erro quadrático médio e viés médio relativo para a estimativa dos parâmetros $K$ e $b$ da isoterma de Freundlich obtidos via método de Gauss-Newton e Levenberg-Marquardt.

Observa-se que os valores encontrados para o viés médio relativo e para o erro quadrático médio das estimativas dos parâmetros da isoterma de Freudnlich obtidos a partir do método de Gauss-Newton e de Levenberg-Marquardt são parecidos, sugerindo que os dois métodos iterativos possuem precisão e acurácia parecidas. O mesmo ocorreu com os valores encontrados para o viés médio relativo e o erro quadrático médio das estimativas dos parâmetros da isoterma de Langmuir-Freundlich.

Os resultados indicam que os dois métodos de estimação apresentam precisão e acurácia parecidas para a estimação dos parâmetros da isoterma de Freundlich e Langmuir-Freundlich. Como o método de Gauss-Newton pode apresentar problemas que impedem a estimação dos parâmetros, a utilização do método de Levenberg-Marquardt é sugerida na estimação dos parâmetros das isotermas estudadas.

Palavras-chave: Isotermas de adsorção, Método de Levenberg-Marquardt, Método de Gauss-Newton

\section{Referências}

[1] V. V. S. Guilarduci, Adsorção de fenol sobre carvão ativado em meio alcalino, Química Nova, 29, 6 (2006) 1226-1232.

[2] M. Lai et al, Equilibrium Isotherms of the Adsorption of Pyrolysis Gases from Polymer Products, Journal of Chemical \& Engineering Data, 55, 2 (2010) 723-727.

[3] A. A. A. Pozza et al, Adsorção e dessorção aniônicas individuais por gibbsita pedogenética, Química Nova, 32, 1 (2009) 99-105.

[4] R Core Team. R: A language and environment for statistical computing. R Foundation for Statistical Computing, Vienna, Austria: R Foundation for Statistical Computing, 2012. Disponível em: $<$ http://www.R-project.org >. Acesso em: 7 fev. 2014. 